\title{
ACUMULAÇÃO TECNOLÓGICA E INOVAÇÃO INDUSTRIAL conceitos, mensuração e evidências no Brasil
}

Paulo N. Figueiredo

\begin{abstract}
Resumo: Este artigo oferece uma contribuição à gestão do processo de desenvolvimento industrial no contexto de economias em desenvolvimento, particularmente no Brasil. Para isso, esclarece certas terminologias relativas a acumulação de capacidade tecnológica e inovação industrial e apresenta um modelo, acompanhado de breve aplicação prática, que pode ser usado para examinar - e gerir - o processo de desenvolvimento industrial. Palavras-chave: Capacidade tecnológica. Inovação industrial. Economias em desenvolvimento.
\end{abstract}

\begin{abstract}
This article offers a contribution to the management of the industrial development process in the context of developing economies, particularly Brazil. The article clarifies certain terminologies relative to technological capability accumulation and industrial innovation. Finally, the article presents a metric, followed by a brief empirical application, that can be used to examine - and manage - the process of industrial development.

Key words: Technological capability. Industrial innovation. Developing economies.
\end{abstract}

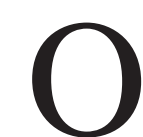
fim da política de substituição de importações, no início dos anos 80, e a intensificação da globalização e da liberalização comercial, durante os anos 90, contribuíram para tornar a acumulação tecnológica fator ainda mais crucial para o crescimento econômico e a competitividade internacional de países em desenvolvimento.

No Brasil, nos últimos 15 anos, tem havido uma profusão de estudos baseados em "diagnósticos", descrições, análises e propostas relativas ao papel da política tecnológica no desenvolvimento econômico e inserção da economia brasileira no mercado internacional. ${ }^{1}$ Porém, ainda há escassez de abordagens gerenciais para estratégias de inovação industrial do ponto de vista de acumulação de capacidade tecnológica. Observa-se ainda o uso indiscriminado de certos termos sem fundamentos analíticos e empíricos adequados, tanto no discurso como em documentos acadêmicos, governamentais e de consultoria, relativos a estratégias de inovação industrial. Isto pode conduzir, de um lado, à realização de estudos cujo foco de análise não capte adequadamente a realidade industrial e, de outro, a uma interpretação equivocada da realidade. Por conseguinte, pode deturpar e interferir negativamente no processo de desenho e implementação de estratégias de inovação industrial, tanto em nível governamental como empresarial.

\section{CAPACIDADE TECNOLÓGICA INOVADORA: FATOR-CHAVE PARA O DESENVOLVIMENTOECONÔMICO}

Embora os benefícios da capacidade tecnológica inovadora para o desenvolvimento econômico de indústrias e países tenham sido observados, desde a Revolução Industrial, por Adam Smith, Alexis de Tocqueville e Karl Marx, foi J. Schumpeter, na década de 30, quem enfatizou a im- 
portância da inovação para o desenvolvimento econômico das nações. Também foi Schumpeter quem nos ensinou que o conceito de inovação não se restringe a produtos e processos, mas envolve novas formas de gestão, novos mercados e novos insumos de produção.

A partir da década de 50, alguns pesquisadores buscaram explicações para questões não abordadas por Schumpeter: fontes de inovação, melhoria contínua e características de empresas inovadoras. Mais especificamente, houve a emergência de um conjunto de estudos dedicados a examinar a capacidade tecnológica, os ativos específicos à empresa ou a base de conhecimento como fontes de diferenças entre empresas em termos de performance competitiva, ainda que no mesmo setor industrial. Essa perspectiva, ancorada na "abordagem baseada em recursos" gerou um conjunto de estudos inspiradores tanto conceituais como empíricos. ${ }^{2}$

No final dos anos 70, começou a emergir um conjunto de estudos que, de maneira mais sistemática, buscava examinar o papel da mudança tecnológica no desenvolvimento industrial e econômico de países e empresas. A partir de raízes intelectuais diversas, tanto no campo da economia como da gestão, essa nova abordagem passou a ser popularmente conhecida como neo-schumpeteriana ou evolucionista. ${ }^{3}$ Vários desses estudos enfatizaram o papel da capacidade tecnológica como fonte de diferenças entre setores industriais e países, em termos de progresso industrial e crescimento econômico.

Um ponto comum nesses estudos é a rejeição à abordagem da economia ortodoxa, na qual a tecnologia era considerada meramente como informação e apenas uma variável exógena nos modelos de desenvolvimento econômico. Os estudos neo-schumpeterianos apontavam o caráter tácito e intrínseco da tecnologia como um dos fatores para explicar a impossibilidade de sua transferência automática de um contexto para outro. Isso, por sua vez, estava no seio das explicações das diferenças entre empresas e setores industriais em termos de performance técnico-econômica. Porém, tais estudos focavam tecnologia e inovação no contexto de empresas e países que já se encontravam em estágio avançado de industrialização.

\section{Desenvolvimento Tecnológico no Contexto de Economias em Crescimento}

No final dos anos 70, sob a influência intelectual da "abordagem baseada em recursos" e da "perspectiva neoschumpeteriana", emergiu um conjunto de estudos sobre o desenvolvimento tecnológico em empresas de países em desenvolvimento - ou de industrialização tardia. Mais especificamente, no início dos anos 70, a pesquisa sobre tecnologia em países em desenvolvimento adotou uma perspectiva dinâmica. Deixando de lado o ponto de vista estático dos economistas ortodoxos - os quais também argumentavam a inexistência de atividades tecnológicas inovadoras em empresas de economias em desenvolvimento - os novos estudos concentram-se nas mudanças ao longo do tempo na tecnologia e na maneira como as empresas implementavam tais mudanças (STEWART; JAMES, 1982). Esses novos estudos, que tiveram origem na América Latina sob a liderança de Jorge Katz, deram grande atenção às mudanças na capacidade tecnológica das empresas ao longo do tempo. ${ }^{4}$ Em seguida, estudos similares foram desenvolvidos na Ásia (BELL et al., 1982; LALL, 1987) e alguns poucos foram implementados na África (MLAWA, 1983). ${ }^{5}$

Durante meados dos anos 90, um novo conjunto de estudos emergiu para examinar as implicações dos processos de aprendizagem na trajetória de acumulação tecnológica de empresas de países em desenvolvimento. ${ }^{6}$ Diferentemente daqueles dos anos 70, essa nova geração de estudos examinou a base organizacional dos processos de aprendizagem e suas implicações para a acumulação tecnológica das empresas. Adotou-se, portanto, uma perspectiva muito mais ampla do que a descrição de trajetórias tecnológicas de firmas, característica dos estudos iniciais. Alguns estudos também examinaram, nas diferenças entre as empresas, o papel dos processos de aprendizagem em termos de acumulação tecnológica e aprimoramento de performance técnico-econômica (FIGUEIREDO, 2001) e o papel da cultura organizacional em termos de acumulação tecnológica (VERA-CRUZ, 2002). O exame da velocidade de acumulação tecnológica, medida em número de anos, aparece em dois estudos dessa literatura (ARIFFIN, 2000; FIGUEIREDO, 2001).

Essas literaturas têm examinado a relação entre acumulação tecnológica e inovação industrial de maneira exaustiva, tanto conceitualmente como empiricamente. Durante os últimos dez anos, houve um considerável avanço na pesquisa sobre esses temas, no contexto de empresas de economias em desenvolvimento. Os estudos têm demonstrado, com adequado grau de detalhe e profundidade $s e \mathrm{e}$ como os processos de aprendizagem afetam a capacidade inovadora e competitiva de empresas. Os resultados, análises e recomendações gerados por tais estudos são fontes valiosas para o aprimoramento de estratégias empre- 
sariais e governamentais de melhoria da performance inovadora e técnico-econômica tanto de empresas como de países. Para a operacionalização das várias recomendações emanadas desses estudos, primeiro faz-se necessário o entendimento de duas questões-chave: o real significado do conceito "capacidade tecnológica" e a maneira apropriada de identificá-la e medi-la.

\section{Capacidade Tecnológica: o que é, afinal? ${ }^{7}$}

Bell e Pavitt (1993; 1995) formularam uma definição ampla, segundo a qual a capacidade tecnológica incorpora os recursos necessários para gerar e gerir mudanças tecnológicas. Tais recursos acumulam-se e incorporam-se aos indivíduos (como aptidões, conhecimentos e experiência) e aos sistemas organizacionais. Essa definição baseia-se em outras formuladas anteriormente. ${ }^{8}$ Além disso, a capacidade tecnológica é de natureza difusa.
A partir da "abordagem baseada nos recursos específicos da firma" (PENROSE, 1959) e valendo-se de evidências empíricas, Bell (1982) faz distinção entre dois tipos de recursos: os que são necessários para usar os sistemas de produção existentes e os que são necessários para mudar os sistemas de produção. Estes últimos não devem ser tomados como um conjunto distinto de recursos especializados pois, por serem de natureza difusa, estão amplamente disseminados por toda a organização.

Em outras palavras, a capacidade tecnológica de uma empresa (ou de um setor industrial) está armazenada, acumulada, em pelo menos quatro componentes (LALL, 1992; BELL; PAVITT, 1993; 1995; FIGUEIREDO, 2001) ${ }^{9}$ apresentados a seguir e ilustrados na Figura 1.

- sistemas técnicos físicos - referem-se à maquinaria e equipamentos, sistemas baseados em tecnologia de informação (como os bancos de dados), software em geral, plantas de manufatura;

FIGURA 1

Dimensões da Capacidade Tecnológica

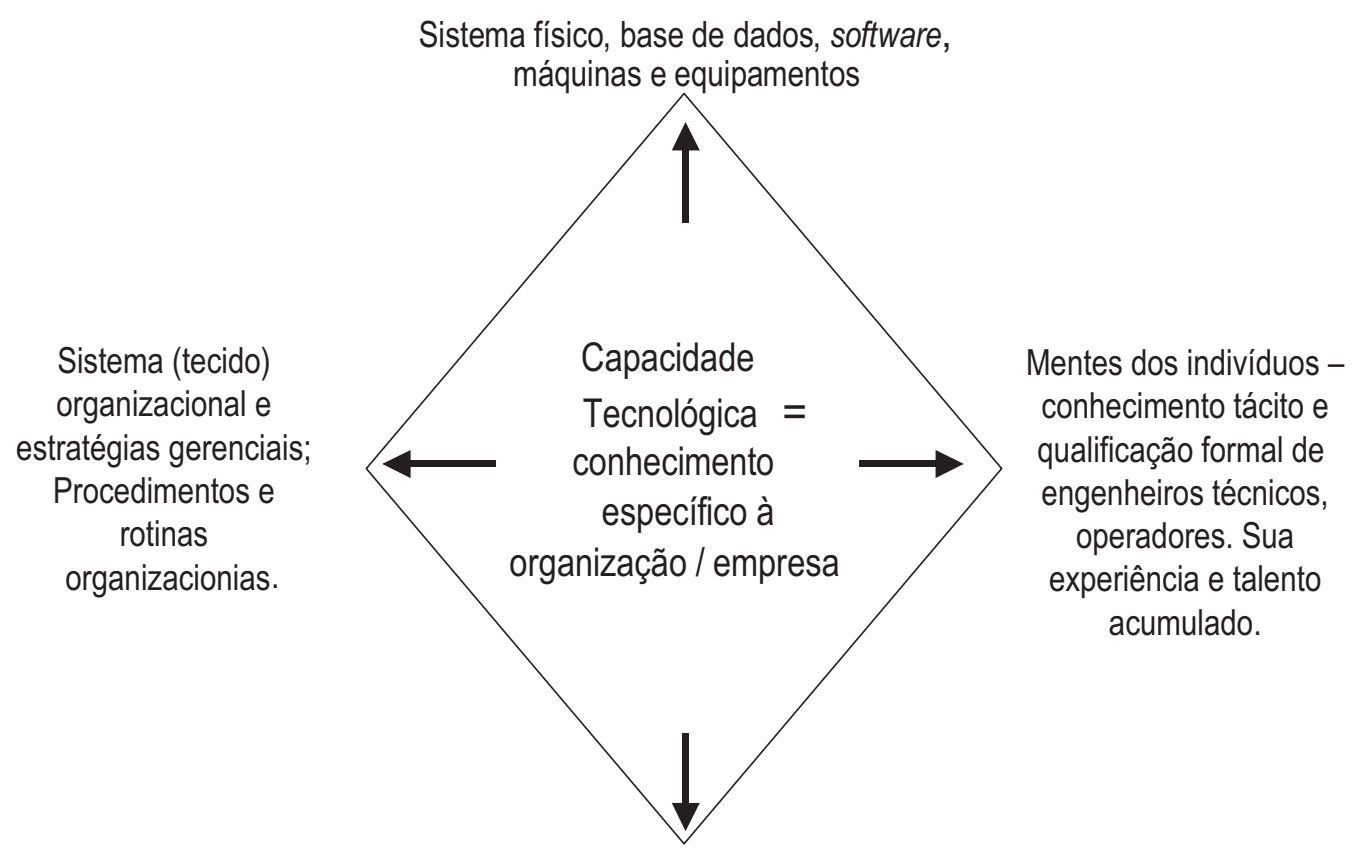

Produtos e Serviços 
- pessoas - referem-se ao conhecimento tácito, às experiências e habilidades de gerentes, engenheiros, técnicos e operadores que são adquiridos ao longo do tempo, mas que também abrangem sua qualificação formal. Essa dimensão tem sido geralmente denominada de "capital humano" da empresa ou do país;

- sistema (tecido) organizacional - refere-se ao conhecimento acumulado nas rotinas organizacionais e gerenciais das empresas, nos procedimentos, nas instruções, na documentação, na implementação de técnicas de gestão (total quality management - TQM; material requirement planning - MRP; just-in-time - JIT, entre outras), nos processos e fluxos de produção de produtos e serviços e nos modos de realizar certas atividades nas organizações;

- produtos e serviços - referem-se à parte mais visível da capacidade tecnológica e refletem o conhecimento tácito das pessoas e da organização e dos seus sistemas físicos e organizacionais. Por exemplo, nas atividades de desenho, desenvolvimento, prototipagem, teste, produção e na parte de comercialização de produtos e serviços, estão refletidos os outros três componentes da capacidade tecnológica.

Portanto, existe uma relação inseparável (simbiótica) entre esses quatro componentes. A capacidade tecnológica possui uma natureza não apenas disseminada, mas abrangente. Ademais, a capacidade tecnológica é intrínseca ao contexto da firma, região ou país onde é desenvolvida (PENROSE, 1959; NELSON; WINTER, 1982; DOSI, 1988a, 1988b). ${ }^{10}$ Logo, é curioso o termo "transferência" de tecnologia. Esse termo pode transmitir a falsa idéia de que a tecnologia pode ser automaticamente transladada de um contexto para outro. No entanto, a real transferência de tecnologia de economias industrializadas para economias em desenvolvimento envolve, de um lado, a gestão da aquisição, instalação e operação da tecnologia importada. De outro, implica assegurar o engajamento da organização recipiente em um contínuo e sistemático processo de aprendizagem tecnológica. É justamente essa segunda "metade" que tende a ser negligenciada em estratégias de inovação industrial. Isso contribui para explicar o processo irregular de desenvolvimento tecnológico que tende a ocorrer em economias em desenvolvimento.

Em razão da natureza tácita e ampla da capacidade tecnológica, aqui não se faz distinção entre capacidade tecnológica e organizacional - ou entre tecnologia e organização -, já que a última é parte integrante da primeira. Porém, há uma tendência a negligenciar-se a dimensão organizacional da capacidade tecnológica. ${ }^{11}$ Ou seja, enquanto costuma-se dar grande ênfase ao "capital humano" como fonte de desenvolvimento tecnológico, dedica-se atenção inadequada ao "capital organizacional", ou seja, à capacidade tecnológica embutida e armazenada no sistema (tecido) organizacional. A adoção de perspectivas limitadas de capacidade tecnológica (como sistema físico ou capital humano) pode ter implicações negativas para implementação de estratégias de inovação industrial. Uma das causas de resultados pífios, em termos de desempenho inovador e/ou técnico-econômico da tecnologia importada para a empresa receptora, é a "compra" de tecnologia limitada aos sistemas físicos e técnicos. Em outras palavras, estratégias industriais que enfocam apenas os elementos mais visíveis da capacidade tecnológica (oferta de capital e de sistemas físicos), sem considerar o desenvolvimento do capital organizacional, conduzem a resultados insignificantes em termos de inovação e produtividade. ${ }^{12}$

Em outros casos, ainda que seja dada forte atenção ao desenvolvimento de "capital humano" para absorver a tecnologia importada, a dimensão organizacional é normalmente negligenciada. Por exemplo, em nossas atividades de trabalho de campo de pesquisa, é comum encontrarmos gerentes que afirmam que, a despeito da presença de máquinas avançadas e de engenheiros e técnicos altamente qualificados, a empresa não consegue obter inovação em produtos e serviços e nem melhorar seu desempenho técnico. Ou seja, como se costuma justificar, falta nas empresas uma "organização" para integrar esses elementos e transformar o conhecimento tácito em novos produtos e práticas de produção. Isso parece refletir, de um lado, a ausência ou inadequação de esforços para aprimorar o tecido organizacional e gerencial no qual a capacidade tecnológica da empresa é acumulada. De outro, reflete uma percepção limitada sobre o que vem a ser "capacidade tecnológica". Por exemplo, é louvável a meta brasileira de formar cerca de 10 mil doutores por ano. Porém, muito embora esse seja um elemento importante do desenvolvimento tecnológico nacional, primeiro é essencial responder a questões como: "Para que e em que áreas a oferta de tal capital humano é relevante para o país?" Em outras palavras, primeiro, é preciso saber como se pretende integrá-los aos demais componentes da capacidade tecnológica nacional. 


\section{MENSURAÇÃO DE CAPACIDADE TECNOLÓGICA}

No que concerne à identificação e medição da capacidade tecnológica em empresas ou setores industriais, particularmente no contexto de economias em desenvolvimento, o que é importante é não apenas identificar se essa capacidade existe ou não, mas também a direção, extensão - ou nível - e velocidade de seu desenvolvimento ou acumulação. Por isso, é preciso levar em conta o princípio básico de gestão, segundo o qual se pode gerir com eficácia aquilo que se pode medir. Antes porém, de introduzir a métrica para este fim, serão comentadas algumas das principais limitações dos indicadores convencionais para identificar e medir a capacidade tecnológica.

\section{Indicadores Convencionais: por que são Limitados?}

Indicadores relativos à base de pesquisa e desenvolvimento (P\&D) e patentes têm sido extensivamente usados para medir a capacidade tecnológica de empresas, setores industriais e países. Normalmente, é realizada avaliação do pessoal alocado em laboratórios de $\mathrm{P} \& \mathrm{D}$, dos gastos em P\&D e da intensidade da atividade de patentes internacionais registradas nos Estados Unidos como parâmetro para inovações internacionalmente reconhecidas. ${ }^{13}$

Há uma vasta literatura internacional, concernente ao contexto de empresas e países tecnologicamente avançados, que mede capacidade tecnológica de firmas e indústrias, à base, por exemplo, de gastos em P\&D (MANSFIELD et al., 1979), qualificações formais de indivíduos (PACK, 1987; JACOBSSON; OSKARSSON, 1995), investimentos em pessoal alocado em laboratórios de P\&D (WORTMAN, 1990) e estatísticas de patentes depositadas nos EUA (PATEL, 1995; PATEL; PAVITT, 1997) e mesmo uma combinação de P\&D, patentes, gastos em educação, e estatísticas de pessoal de engenharia (DANIELS, 1997). Além disso, há o Manual de Oslo (OECD, 1997) que, embora tenha avançado em relação ao padrão de medida anterior (Manual Frascati), adota como critério-chave a medição de atividades tecnológicas por meio de estatísticas de P\&D.

No Brasil, a combinação de estatísticas de patentes e outras medidas quantitativas - como gastos em P\&D, educação, percentual de cientistas e engenheiros qualificados e intensidade de capital - tem sido usada em alguns estudos para medir a capacidade tecnológica (MACEDO; ALBUQUERQUE, 1999; QUADROS et al., 2001; ANDREASSI; SBRAGIA, 2002; KANNEBLEY, 2003). Tais estudos são extremamente meritórios ao apresentarem uma perspectiva agregada das atividades tecnológicas em empresas no Brasil. Vários deles têm suas raízes na literatura internacional sobre fatores determinantes das atividades inovadoras no âmbito empresarial (como COHEN; LEVIN, 1989; COHEN; LEVINTHAL, 1990; KUMAR; SIDDHARTHAN, 1997).

Porém, como argumentado em Lall (1992), Bell e Pavitt (1993; 1995), Dutrénit (2000), Ariffin (2000) e Figueiredo (2001; 2003a; 2003b), há situações em que algumas dessas medidas têm suas próprias limitações e são menos relevantes pelas seguintes razões:

- indicadores relativos às atividades de $\mathrm{P} \& \mathrm{D}$ e de patentes são apenas prevalentes em alguns setores industriais de países tecnologicamente avançados (como por exemplo, Estados Unidos, Japão, Reino Unido e Alemanha), onde certas empresas têm níveis suficientemente profundos de P\&D e intensiva produção de patentes internacionais. Logo, a aplicação desses indicadores para empresas em economias em desenvolvimento - que, em geral, não possuem níveis sofisticados de capacidade tecnológica inovadora para conduzir atividades de $\mathrm{P} \& \mathrm{D}$ e patentes - seria irrelevante;

- estatísticas de patentes internacionais, particularmente patentes nos Estados Unidos, são geralmente aceitas como uma medida superior de capacidade tecnológica. Estão disponíveis por longo período de tempo e fornecem detalhes estatísticos altamente quantificáveis, que poderiam ser examinados de acordo com a localização geográfica e área técnica (PATEL, 1995). Entretanto, muito embora isso seja verdadeiro, avaliar capacidades tecnológicas tendo como base essas estatísticas internacionais poderia ser limitante e tendencioso para empresas em economias em desenvolvimento que não exportam significativamente produtos especializados e de marca própria para o mercado dos EUA.

- nas empresas que operam em economias em desenvolvimento (América Latina, Ásia, África do Sul ou alguns países do Oriente Médio e Leste Europeu) é rara a incidência de laboratórios de $\mathrm{P} \& \mathrm{D}$ formalmente estruturados conforme os encontrados em empresas de economias industrializadas. Não obstante, atividades tecnológicas inovadoras e complexas são conduzidas através dos departamentos de engenharia, de qualidade e de manutenção. É muitas vezes nessas unidades organizacionais que está acumulada grande parte das capacidades tecnológicas inovadoras das empresas;

- a maneira como a empresa constrói a sua base organizacional influencia no sucesso ou fracasso de seu engajamento em atividades inovadoras - de básicas à P\&D . 
Porém, as abordagens baseadas em indicadores convencionais não captam as características e elementos do tecido organizacional, no qual a capacidade tecnológica é desenvolvida, acumulada e sustentada.

- outro problema dos estudos baseados em estatísticas de indicadores convencionais é que eles examinam a capacidade tecnológica em um ponto no tempo (momento atual snap-shot studies). ${ }^{14}$ Tal abordagem estática não permite esclarecer como empresas desenvolveram progressivamente níveis mais profundos de capacidade tecnológica. Ou seja, não há exame do processo de acumulação tecnológica.

Subjacente à persistência do uso desses indicadores convencionais para medir capacidade tecnológica no contexto de economias em desenvolvimento, está uma perspectiva de inovação que tende a negligenciar tanto as atividades de imitação, cópia, adaptação, experimentação, como a adoção de novos produtos e processos e de novos arranjos organizacionais que são parte do processo inovador (DOSI, 1988a; 1988b; LALL, 1992). Tais atividades são essenciais para o entendimento do processo de desenvolvimento tecnológico em economias em desenvolvimento (BELL; PAVITT, 1993, 1995; DUTRÉNIT, 2000; ARIFFIN, 2000; FIGUEIREDO, 2001). Ou seja, há diversos graus de inovação - de básica a complexa - que não são captados pelos estudos à base de indicadores convencionais. Identificar a progressão por meio dos diferentes estágios de desenvolvimento tecnológico é crucial para entender a dinâmica industrial de economias e regiões em desenvolvimento. Para isso, é fundamental examinar os diferentes estágios percorridos por empresas e setores industriais.

\section{Métrica Alternativa para Identificar e Medir a Capacidade Tecnológica}

Baseando-se em Katz (1987), Dahlman et al. (1987) e Lall (1987; 1992; 1994) desenvolveu um modelo no qual as capacidades tecnológicas de uma empresa são categorizadas por funções. Tal modelo sugere que a acumulação processa-se a partir das categorias mais simples para as mais complexas. ${ }^{15} \mathrm{O}$ princípio dessa métrica começou a ser desenvolvido pelo clássico estudioso russo Alexander Gerschenkron (1962), com base na idéia de estágios de desenvolvimento no contexto de industrialização tardia. Depois, outro avanço significativo foi feito em Lall (1992) e, mais tarde, refinada em Bell e Pavitt (1995). Em Figueiredo (2001), esse modelo foi empiricamente adaptado para explicitar melhor as diferenças entre empresas do setor de aço, em termos da maneira e da taxa (velocidade) de acumulação de capacidade tecnológica e em termos de aprimoramento de desempenho técnico-econômico (ver o modelo adaptado no Quadro 1). ${ }^{16}$

Em outras palavras, o modelo permite identificar e medir a acumulação de capacidade tecnológica baseada em atividades que a empresa é capaz de realizar ao longo de sua existência. Com base nesse modelo, é possível distinguir entre: capacidades rotineiras e capacitações inovadoras. As primeiras são para usar ou operar certa tecnologia e sistemas de produção, enquanto as segundas são para adaptar e/ou desenvolver novos processos de produção, sistemas organizacionais, produtos, equipamentos e projetos de engenharia (isto é, para gerar e gerir a inovação tecnológica).

O Quadro 1 apresenta um exemplo do modelo modificado para aplicação empírica. Embora essa adaptação tenha sido feita, inicialmente, para a indústria do aço, o modelo tem sido utilizado para estudos de desenvolvimento tecnológico em outros setores industriais, como será apresentado com mais detalhes a seguir. ${ }^{17}$ A capacidade tecnológica por função e nível de dificuldade é medida pelo tipo de atividade que a empresa é capaz de realizar por si mesma em diferentes intervalos de tempo.

Com relação à aplicação empírica desse modelo, é importante notar os seguintes pontos:

- O modelo permite captar dois tipos de trajetória de desenvolvimento tecnológico: pela evolução da simples produção de bens e serviços cada vez mais complexos e de maior valor agregado e pelo aprofundamento do nível de capacidade tecnológica. No primeiro caso, estuda-se, por exemplo, a evolução da manufatura de simples aparelhos de áudio à de DVDs. No segundo, pode-se analisar a produção básica para a engenharia, desenho e desenvolvimento de processos e/ou produtos.

- Embora apresente a capacidade tecnológica em níveis ou "estágios", como em Gerschenkron (1962), o modelo não pressupõe que todas as empresas de um certo setor industrial - e até mesmo unidades de uma mesma empresa necessariamente capacitem-se nessa seqüência linear. $\mathrm{O}$ modelo também não pressupõe que as capacidades sejam construídas, acumuladas, sustentadas (ou debilitadas), ao mesmo tempo e à mesma velocidade, para as diferentes funções tecnológicas. Ademais, é difícil fazer uma separação entre as atividades relacionadas aos produtos e o processo de sua fabricação, incluindo-se aí o instrumental e o equipamento utilizado. 
QUADRO 1

Modelo Descritivo da Capacidade Tecnológica em Empresas de Economias Emergentes

\begin{tabular}{|c|c|c|c|c|c|}
\hline \multirow{3}{*}{$\begin{array}{l}\text { Niveis de } \\
\text { Competências } \\
\text { Tecnológicas }\end{array}$} & \multicolumn{5}{|c|}{ Funçōes Tecnológicas e Atividades Relacionadas } \\
\hline & \multicolumn{2}{|c|}{$\begin{array}{c}\text { Investimentos } \\
\text { Decisão e Controle sobre a Planta }\end{array}$} & \multirow{2}{*}{$\begin{array}{c}\text { Processos e Organização } \\
\text { da Produçăo }\end{array}$} & \multirow[t]{2}{*}{ Produtos } & \multirow[t]{2}{*}{ Equipamentos } \\
\hline & Decisão e Controle sobre a Planta & Engenharia de Projetos & & & \\
\hline $\begin{array}{l}(1) \\
\text { Básico }\end{array}$ & $\begin{array}{l}\text { Decisão sobre localização da planta. } \\
\text { Termos de referência. }\end{array}$ & $\begin{array}{l}\text { Preparação inicial de projeto. } \\
\text { Sincronizaçăa de trabalhos de } \\
\text { construçāo civil e instalaçōes. }\end{array}$ & $\begin{array}{l}\text { Coordenacăo de rotina na planta. Absorção } \\
\text { da capacidade da planta. PCP e CQ } \\
\text { básicos. }\end{array}$ & $\begin{array}{l}\text { Replicação de aços seguindo especificaçōes } \\
\text { amplamente aceitas. CQ de rotina. } \\
\text { Fornecimento a mercados de exportação. }\end{array}$ & $\begin{array}{l}\text { Reposiçãão de rotina de componentes de } \\
\text { equipamento. Participação em } \\
\text { instalaçôes e testes de performance. }\end{array}$ \\
\hline $\begin{array}{c}(2) \\
\text { Renovado }\end{array}$ & $\begin{array}{l}\text { Monitoramento ativo de rotina de } \\
\text { unidades existentes na planta. }\end{array}$ & $\begin{array}{l}\text { Serviços rotineiros de engenharia na } \\
\text { planta nova e/ou existente. }\end{array}$ & $\begin{array}{l}\text { Estabilidade do AF e aciaria. Coordenação } \\
\text { aprimorada da planta. Obtençăo de } \\
\text { certificaçăão (ex.: ISO 9002, QS 9000) }\end{array}$ & $\begin{array}{l}\text { Replicação aprimorada de especificacacōes de } \\
\text { aços dados ou próprias. Obtençăo de } \\
\text { certificaçăo internacional para CQ de rotina. }\end{array}$ & $\begin{array}{l}\text { Manufatura e reposiçāo de componentes } \\
\text { (ex.: cilindros) sob certificaçăa } \\
\text { internacional (ISO 9002) }\end{array}$ \\
\hline & & & \multicolumn{3}{|l|}{ CAPACIDADES INOVADORAS } \\
\hline $\begin{array}{l}(3) \\
\text { Extra-básico }\end{array}$ & $\begin{array}{l}\text { Envolvimento ativo em fontes de } \\
\text { financiamento de tecnologia. }\end{array}$ & $\begin{array}{l}\text { Planejamento de projeto. Estudos de } \\
\text { viabilidade tecnicamente assistidos, } \\
\text { para grandes expansões. }\end{array}$ & $\begin{array}{l}\text { Pequenas adaptaçōes e intermitentes em } \\
\text { processos, eliminação de gargalos, e } \\
\text { alongamento de capacidade. }\end{array}$ & \begin{tabular}{|l|} 
Pequenas adaptaçōes em especificaçōes \\
dadas. Criaçāo de especificaçōes próprias para \\
aços (dimensão, forma, propriedades \\
mecânicas).
\end{tabular} & $\begin{array}{l}\text { Pequenas adaptaçōes em equipamentos } \\
\text { para ajustá--os a matérias-primas locais. } \\
\text { Manutençăo break-down. }\end{array}$ \\
\hline$\stackrel{(4)}{\text { Pré-Intermediário }}$ & $\begin{array}{l}\text { Monitoramento parcial e controle de } \\
\text { estudos de viabilidade de expansão, } \\
\text { busca, avaliação, e seleçãa de } \\
\text { tecnologia e fornecedores. }\end{array}$ & $\begin{array}{l}\text { Engenharia de instalaçōes. Expansões } \\
\text { tecnicamente assistidas. Engenharia } \\
\text { de detalhamento. }\end{array}$ & $\begin{array}{l}\text { Alongamentos sistemáticos de capacidade. } \\
\text { Manipulação de parâmetros-chave de } \\
\text { processo. Novas técnicas organizacionais } \\
\text { (TQC/M, ZD, ITT). }\end{array}$ & $\begin{array}{l}\text { Aprimoramentos sistemáticos em especificaçōes } \\
\text { dadas. 'Engenharia reversa' sistemática. } \\
\text { Desenho e desenvolvimento de aços } \\
\text { tecnicamente assistidos. Desenvolvimento de } \\
\text { especificaçōes próprias. }\end{array}$ & $\begin{array}{l}\text { Reforma de grandes equipamentos (ex.: } \\
\text { AF) sem assistência técnica. Engenharia } \\
\text { reversa de detallhe e básica. Manufatura } \\
\text { de grandes equipamentos. }\end{array}$ \\
\hline $\begin{array}{c}\text { (5) } \\
\text { Intermediário }\end{array}$ & $\begin{array}{l}\text { Monitoramento completo, controle e } \\
\text { execucuăo de estudos de viabilidade, } \\
\text { busca, avaliação, seleçãa, e } \\
\text { atividades de financiamento. }\end{array}$ & $\begin{array}{l}\text { Engenharia básica de plantas } \\
\text { individuais. Expansão da planta sem } \\
\text { assistência técnica. Provisão } \\
\text { intermitente de assistência técnica. }\end{array}$ & $\begin{array}{l}\text { Aprimoramento continuo de processo. } \\
\text { Desenho de sistemas automatizados } \\
\text { estáticos. Integração de sistemas } \\
\text { automatizados de processo e PCP. } \\
\text { Alongamento rotinizado de capacidade. }\end{array}$ & $\begin{array}{l}\text { Aprimoramento continuo em especificaçōes } \\
\text { próprias. Desenho, desenviolvimento, } \\
\text { manufatura e comercializacăa,o, de aços } \\
\text { complexos e de alto valor sem assistência } \\
\text { técnica. Certificação para desenvolvimento de } \\
\text { produto (ex.: ISO 9001). }\end{array}$ & $\begin{array}{l}\text { Continua engenharia básica e de detalhe } \\
\text { e manufatura de plantas individuais (ex.: } \\
\text { AF, Sinter). Manutençăo preventiva. }\end{array}$ \\
\hline $\begin{array}{l}(6) \\
\text { Intermediário } \\
\text { Superior }\end{array}$ & $\begin{array}{l}\text { Elaboração e execução próprias de } \\
\text { projetos. Provisão de assistência } \\
\text { técnica em decisões de investimentos. }\end{array}$ & $\begin{array}{l}\text { Engenharia básica da planta inteira. } \\
\text { Provisão sistemática de assistência } \\
\text { técnica em estudos de viabilidade, } \\
\text { engenharia de aquisição, de detalhe, } \\
\text { básica, e partida da planta. }\end{array}$ & $\begin{array}{l}\text { Integração entre sistemas operacionais e } \\
\text { sistemas corporativos. Engajamento em } \\
\text { processos de inovação baseados em } \\
\text { pesquisa e engenharia. }\end{array}$ & $\begin{array}{l}\text { Adiçăo de valor a aços desenvolvidos } \\
\text { internamente. Desenho e desenvolvimento de } \\
\text { aços extra complexos e de alto valor agregado. } \\
\text { Engajamento em projetos de desenho e } \\
\text { desenvolvimento com usuários. }\end{array}$ & $\begin{array}{l}\text { Continua E básica e detalhe de } \\
\text { equipamento para planta inteira de aço } \\
\text { elou componentes para outras } \\
\text { indústrias. Assistência técnica (ex.: } \\
\text { reforma de AF) para outras empresas. }\end{array}$ \\
\hline $\begin{array}{c}\text { (7) } \\
\text { Avançado }\end{array}$ & $\begin{array}{l}\text { Gestão de projetos de classe mundial. } \\
\text { Desenvolvimento de novos sistemas } \\
\text { de produção via P\&D. }\end{array}$ & $\begin{array}{l}\text { Engenharia de classe mundial. Novos } \\
\text { desenhos de processos e P\&D } \\
\text { relacionado. }\end{array}$ & $\begin{array}{l}\text { Produção de classe mundial. Desenhos e } \\
\text { desenvolvimento de novos processos } \\
\text { baseados em E e P\&D. }\end{array}$ & $\begin{array}{l}\text { Desenho e desenvolvimento de produtos em } \\
\text { classe mundial. Desenho original via E, Pe D. }\end{array}$ & $\begin{array}{l}\text { Desenho e manufaturara de equipamentos } \\
\text { de classe mundial. P\&D para novos } \\
\text { equipamentos e componentes. }\end{array}$ \\
\hline
\end{tabular}

- Em estudos no âmbito de empresas - e mesmo de setores industriais - recomenda-se classificar as funções tecnológicas específicas (como produtos, processo e organização da produção), em termos de tipos e níveis de capacidades, em vez da empresa ou do setor industrial em si (DUTRÉNIT, 2000; FIGUEIREDO, 2003a; 2003b). As empresas acumulam suas capacidades para funções tecnológicas diversas, de várias maneiras, em diferentes direções e velocidades. Para certa função tecnológica (produtos, por exemplo) pode-se alcançar uma profundidade de capacidade tecnológica (nível 5), enquanto que em uma outra função (gestão de projetos) pode-se acumular um nível mais superficial (nível 2).

- Lembrando que as capacidades rotineiras e inovadoras acumulam-se de maneira paralela dentro da empresa, e também do setor industrial, é possível acumular partes de certas capacidades inovadoras sem que o acúmulo de suas capacidades rotineiras esteja consolidado. Chamamos a esse fenômeno "acumulação truncada ou incompleta", observado, com certa freqüência, em empresas que operam em economias ou áreas emergentes (DUTRÉNIT, 2000; ARIFFIN, 2000; FIGUEIREDO, 2001, 2003a).

A aplicação empírica mais sofisticada desse modelo permite ainda examinar a velocidade (ou taxa) de acumulação - isto é, o número de anos que uma empresa ou setor in- dustrial leva para alcançar determinado nível de capacidade para funções tecnológicas específicas. Também é possível identificar quanto tempo uma empresa - ou conjunto de empresas - permaneceu estacionada em certo nível de capacidade tecnológica. A identificação e o exame da progressão por meio dos diferentes estágios de desenvolvimento tecnológico é crucial para entender a dinâmica industrial de economias e regiões em desenvolvimento (KATZ, 1987; LALL, 1992; BELL; PAVITT, 1993; 1995).

Exemplos de medições da velocidade de acumulação de capacidade tecnológica são apresentados em Figueiredo (2001; 2002; 2003a), enquanto Ariffin desenvolve um método e sua aplicação empírica sistemática na indústria eletroeletrônica (2000). Essa preocupação em medir o tempo de acumulação tecnológica presente nesses dois estudos ainda é uma questão negligenciada em estudos empíricos e em estratégias de inovação industrial - embora seja crucial para empresas de economias emergentes, como foi já mencionado nesse artigo.

Como uma extensão do modelo no Quadro 1, o Gráfico 1 (a "escada") é uma estrutura auxiliar, que facilita a visualização da trajetória tecnológica de empresas de economias em desenvolvimento. Tão importante quanto focalizar a acumulação do nível mais avançado de capacidade tecnológica, é entender que a construção e a acumu- 
lação dessa capacidade em níveis intermediários são uma pré-condição para o alcance de patamares mais elevados (DOSI, 1988a; LALL, 1992; HOBDAY, 1995; BELL; PAVITT, 1993, 1995; DUTRÉNIT, 2000; ARIFFIN, 2000; FIGUEIREDO, 2001, 2003a). Entretanto, estudos sobre inovação industrial em economias em desenvolvimento tendem a ignorar os seguintes aspectos: a importância da acumulação de capacidades em níveis intermediários e como e em quanto tempo as empresas evoluem da acumulação de capacidades rotineiras para inovadoras - de básicas a avançadas.

Por isso, a aplicação empírica dos modelos apresentados no Quadro 1 e no Gráfico 1 permite levantar questões aparentemente simples. Mas a busca sistemática e disciplinada de respostas para elas pode conduzir a uma estratégia de inovação industrial focada e coerente - tanto no âmbito de empresas como de setores industriais ou até mesmo de um país. As questões são:
- onde estamos em termos de capacidade tecnológica?;

- quanto tempo levamos para chegar até aqui?;

- por quanto tempo estamos "estacionados" em um determinado nível de capacidade para uma função tecnológica específica?;

- quão distante estamos da fronteira tecnológica internacional?;

- onde queremos estar até o ano $x$ ?;

- quais são os recursos e como geri-los para alcançar um nível de capacidade tecnológica em $x$ número de anos?

\section{APLICAÇÃO EMPÍRICA DA MÉTRICA DE CAPACIDADE TECNOLÓGICA}

Apresenta-se a seguir uma breve aplicação empírica do modelo de mensuração de capacidade tecnológica. Isso foi

\section{GRÁFICO 1}

Modelo llustrativo de Trajetória de Acumulação de Capacidade Tecnológica em Empresas de Economias Emergentes (Escada de Capacidades Tecnológicas)

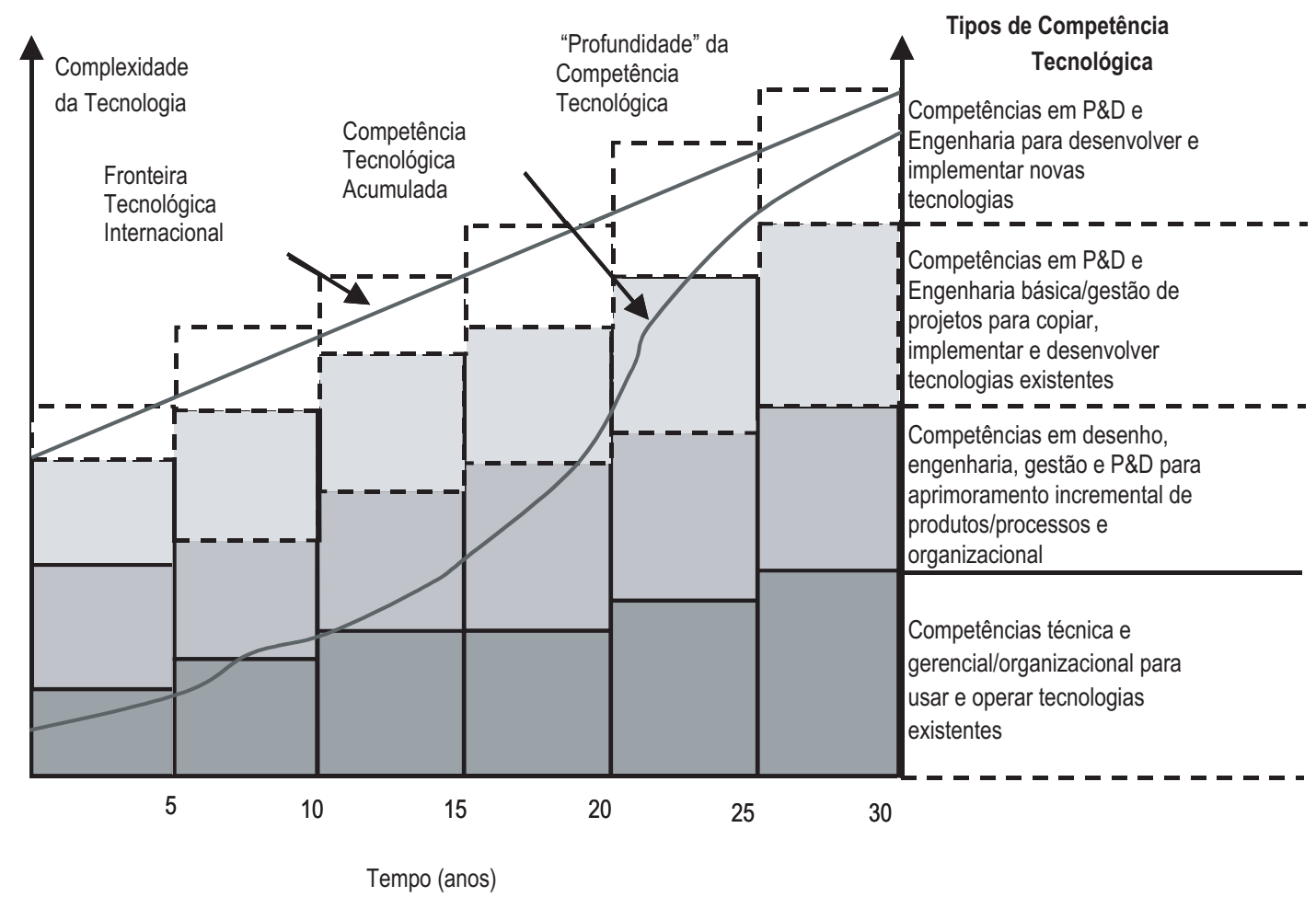

Fonte: Bell (1997)

Nota: Ver aplicação empirica em Figueiredo (2001; 2003b). 
feito com base em recente estudo sobre desenvolvimento tecnológico na indústria de tecnologia de informação e comunicação (TIC) no Brasil (FIGUEIREDO; MARINS, 2005). O estudo examinou o desenvolvimento de capacidades tecnológicas em 18 dos mais importantes institutos de pesquisa e desenvolvimento (P\&D) vocacionados para o setor de TIC localizados nas regiões Sul, Sudeste, Nordeste e Norte. ${ }^{18}$

A composição da amostra obedeceu a três critérios: localização; idade; e natureza dos institutos. Localização refere-se à dispersão geográfica dos institutos de P\&D no território nacional. Assim, a amostra foi composta por institutos geograficamente distribuídos em todas as regiões do Brasil.

Quanto à idade dos institutos de $\mathrm{P} \& \mathrm{D}$ foram pesquisados desde aqueles criados na década de 60 até os mais recentes, como de 2001. Por fim, examinou-se institutos de natureza diversa: tanto públicos como privados, tanto ligados a universidades quanto independentes ou ligados a empresas. Portanto, foi obtida uma amostra representativa, rica em evidências e diversificada.

Para examinar as questões pesquisadas com adequado detalhamento e profundidade, foi necessária a coleta de evidências empíricas primárias. Tais evidências foram coletadas por meio de fontes variadas: entrevistas, observação direta e análise de documentação. Em razão das idades diferentes dos institutos - e no intuito de obter-se comparações interessantes - foi criada uma estrutura de três fases comuns:

- fase inicial: período em que começam suas atividades;

- fase intermediária: período de transição da primeira fase para a última - marcada pelo amadurecimento tecnológico e pela adaptação a condições externas (como a desregulamentação e a privatização do setor de telecomunicações nacional e a criação da Lei de Informática);

\section{- fase atual.}

Para o exame da capacidade tecnológica nas organizações da amostra, foi construída uma métrica específica para esse tipo de indústria com base em extensivo trabalho de adaptação, calibração e validação (ver o modelo adaptado no Quadro 2). Quanto aos tipos, foram examinadas as capacidades construídas pelos institutos em quatro funções tecnológicas: engenharia de software; gestão de projetos; produtos e soluções; e ferramentas e processos. As capacidades tecnológicas foram divididas em seis níveis de complexidade crescente, sendo que os níveis 1 e 2 representam as capacidades de rotina e os níveis de 3 a 6 representam as capacidades para inovar. O estudo encontrou uma diversidade de tipos e níveis de capacidades tecnológicas inovadoras na amostra examinada, conforme mostrado na Tabela 1.

As principais evidências relativas ao estágio atual da capacidade tecnológica dos participantes da amostra são: - A função tecnológica "engenharia de software" é a que concentra mais institutos nos níveis 5 e 6 ("intermediáriosuperior" e "avançado", respectivamente). Embora apenas um deles (correspondente a 5,5\% da amostra) tenha alcançado as capacidades de nível 6 , as capacidades de nível 5 representam o máximo de capacitação de onze participantes $(61,1 \%)$.

- As capacidades de nível 4 (“intermediário”), representam o grau máximo de capacitação na função "engenharia de software" em seis institutos pesquisados (33,3\%). O instituto que consolidou as capacidades de nível 6 representa um centro de referência mundial no desenvolvimento de determinada tecnologia. Em termos de "gestão de projetos", o nível 4 ("intermediário") é o que concentra maior número de participantes e 12 institutos o têm como nível máximo alcançado (66,6\% da amostra).

- O nível 3 (“inovação básica”) representa o grau máximo alcançado por quatro participantes $(22,0 \%)$.

- O nível 5 (“intermediário-superior”) representa o grau máximo de capacitação em "gestão de projetos" de dois institutos estudados $(11,1 \%)$ - sendo um deles independente e o outro ligado a uma empresa.

Muito embora nenhum instituto estudado tenha consolidado as capacidades de nível 6 ("avançado") em "gestão de projetos", um dos participantes da amostra encontra-se em processo de transição para aquele nível. Nesse instituto há esforços deliberados no sentido de transformar a prevenção de falhas e defeitos durante a realização de um projeto (não apenas em produtos, mas também em processos) em uma rotina estruturada e formalizada.

A função "produtos e soluções" é a única em que os participantes da amostra estão distribuídos em torno de quatro níveis de especialização máxima, estando apenas um deles $(5,5 \%)$ restrito ao nível 3 (“inovação básica”). O nível 4 ("intermediário") concentra dez institutos estudados $(55,5 \%)$. Os níveis 5 ("intermediário-superior") e 6 ("avançado") representam o nível máximo alcançado por seis e por um participante $(33,3 \%$ e $5,5 \%$, respectivamente). As evidências apontam que o instituto que alcançou o nível 6 de capacitação nessa função é capaz de desenvolver produtos e soluções de elevada complexi- 
dade, dotados de capacidade de personalização para atender necessidades ainda não identificadas. Além disso, há a geração de spin-offs por conta da complexidade e da especialização das atividades em que esse instituto vem se engajando.

Finalmente, em relação a "ferramentas e processos", os institutos estudados estão agrupados em três níveis de capacitação tecnológica: 10 (55,5\%) encontram-se no nível 3 ("inovação básica"); 7 (38,8\%) no nível 4 ("intermediário"); e 1 (5,5\%), que é um instituto independente, no nível 5 ("intermediário-superior").

As evidências indicam que os institutos têm buscado organizar suas atividades em torno de métodos de trabalho internacionalmente praticados. No entanto, embora uma parte significativa deles esteja orientada para a organização de suas práticas em torno de padrões internacionais, as evidências sugerem que poucos são os que, ao se organizarem e obterem certificações, voltaram-se para o de- senvolvimento de práticas próprias e de processos adequados a suas especificidades.

Além disso, assim como o ocorrido com a função "gestão de projetos", não há institutos que tenham consolidado as capacidades de nível 6 ("avançado") na função "ferramentas e processos". As evidências sugerem a ausência de institutos que venham realizando o aprimoramento contínuo de processos e sistemas operacionais próprios, uma vez que muitos nem mesmo estruturaram por completo seus processos organizacionais e operacionais.

Portanto, o estudo contribuiu para elucidar a realidade desse segmento da indústria de TIC no Brasil. Tal realidade é, por vezes, desconhecida justamente pela escassez ou ausência de estudos dessa natureza. Isso contribui para a emergência de certas generalizações comuns sobre o desenvolvimento tecnológico na América Latina e no Brasil. É assim que, com base em análises agregadas, tem-se argumentado que a partir da década de 90 iniciou-se um pro-

\section{QUADRO 2}

Modelo Descritivo para Mensurar as Capacidades Tecnológicas no Setor de Tecnologia de Informação e Comunicação

\begin{tabular}{|c|c|c|c|c|}
\hline \multirow{2}{*}{$\begin{array}{l}\text { Niveis de } \\
\text { Competência }\end{array}$} & \multicolumn{2}{|c|}{ Atividades de Engenharia e Gestão de Projetos } & \multirow{2}{*}{ Produtos e Soluçōes } & \multirow{2}{*}{ Ferramentas e Processos } \\
\hline & Engenharia de Software & Gestão de Projetos & & \\
\hline \multicolumn{5}{|c|}{ CAPACIDADES DE ROTINA } \\
\hline $\begin{array}{l}\text { Nivel } 1 \\
\text { Básico }\end{array}$ & \begin{tabular}{|l|}
$\begin{array}{l}\text { Ferramentas básicas e tecnologias pré-existentes } \\
\text { de desenvolvimento de software. Práticas de } \\
\text { gestão incipientes. Ambiente instável para o } \\
\text { desenvolvimento de software e atividades de P\&D } \\
\text { correlacionadas. }\end{array}$ \\
\end{tabular} & $\begin{array}{l}\text { Práticas internas de gestão de projetos informais e } \\
\text { intermitentes. Imprevisibilidade de prazos, } \\
\text { orçamentos, funcionalidade e qualidade do } \\
\text { produto. Gestão de projetos realizada pelos } \\
\text { clientes. }\end{array}$ & $\begin{array}{l}\text { Replicação de especificaçōes determinadas pelos } \\
\text { clientes. Pequenas adaptaçōes de tecnologias já } \\
\text { existentes. }\end{array}$ & $\begin{array}{l}\text { Uso de ferramentas básicas de engenharia de } \\
\text { software. Processos operacionais não-formalizados. } \\
\text { Técnicas de controle de qualidade incipientes. }\end{array}$ \\
\hline $\begin{array}{c}\text { Nivel } 2 \\
\text { Extra básico }\end{array}$ & $\begin{array}{l}\text { Utilização e adaptação de tecnologias } \\
\text { desenvolvidas por terceiros. Formalização das } \\
\text { práticas básicas de engenharia de software. }\end{array}$ & $\begin{array}{l}\text { Gestão de projetos realizada informalmente, com } \\
\text { base nas práticas dos clientes. Padronização das } \\
\text { fases básicas de um projeto (ex.: planejamento, } \\
\text { testes e desenvolvimento). Gestão de projetos } \\
\text { abrangendo fornecedores e sub-contratados. }\end{array}$ & $\begin{array}{l}\text { Atividades de reengenharia e cópia. Novas aplicaçōes } \\
\text { para tecnologias e produtos, visando ao atendimento } \\
\text { das necessidades pontuais da empresa-cliente. }\end{array}$ & $\begin{array}{l}\text { Estruturação dos processos operacionais. Controle } \\
\text { de documentos operacionais e gerenciais. Controle } \\
\text { de instruçōes técnicas para projetos. Uso de canais } \\
\text { de comunicação em redes compartihadas. }\end{array}$ \\
\hline \multicolumn{5}{|c|}{ CAPACIDADES INOVADORAS } \\
\hline $\begin{array}{l}\text { Nivel } 3 \\
\text { Inovação } \\
\text { básica }\end{array}$ & $\begin{array}{l}\text { Processos de desenvolvimento de software } \\
\text { estruturados e padronizados. Interação com } \\
\text { clientes e parceiros para desenvolvimento de } \\
\text { novas tecnologias. }\end{array}$ & $\begin{array}{l}\text { Planejamento e coordenação formal de projetos } \\
\text { simples. Capacidade de gestão de projetos } \\
\text { baseada na performance de projetos anteriores. } \\
\text { Capacidade de identificaçãao dos riscos dos } \\
\text { projetos. Sistemas de controle de documentação } \\
\text { de projetos. Capacitaçăão de gerentes de projeto. }\end{array}$ & $\begin{array}{l}\text { Processo de identificação das necessidades da } \\
\text { empresa-cliente. Desenvolvimento de produtos e } \\
\text { soluçōes para solucionar problemas específicos. } \\
\text { Análise, definiçãa e especificação de requisitos. }\end{array}$ & $\begin{array}{l}\text { Sistemas institucionais para integração de } \\
\text { informaçōes e dados (ex.: base de projetos). } \\
\text { Padronização do processo de desenvolvimento de } \\
\text { soffware. Capacitação em metodologias de gestão } \\
\text { de processos. Práticas operacionais orientadas por } \\
\text { pré-requisitos e especificaçōes CMM2. }\end{array}$ \\
\hline $\begin{array}{c}\text { Nivel } 4 \\
\text { Intermediário }\end{array}$ & $\begin{array}{l}\text { Integração das ferramentas do instituto com as } \\
\text { utilizadas por clientes e parceiros. } \\
\text { Complementaridade das atividades de P\&D para } \\
\text { viabilizar o desenvolvimento de tecnologias } \\
\text { inovadoras. }\end{array}$ & $\begin{array}{l}\text { Gestão de projetos complexos, envolvendo áreas } \\
\text { de especialização tecnológica complementares. } \\
\text { Interação continua entre gerentes de projeto do } \\
\text { instituto e gerentes de projeto dos clientes. } \\
\text { Documentação formal das fases do projeto em } \\
\text { base de dados. }\end{array}$ & $\begin{array}{l}\text { Tecnologias inovadoras visando ao mercado em } \\
\text { potencial. Soluçōes complexas a partir da integração de } \\
\text { áreas de especialização (ex.: óptica, Java, } \\
\text { reconhecimento de voz). }\end{array}$ & $\begin{array}{l}\text { Criação de novas unidades organizacionais. } \\
\text { Fortalecimento das práticas de gestão de projetos. } \\
\text { Gestão estratégica da qualidade; obtenção de } \\
\text { certificaçōes internacionais (ISO, PMP-PMI). } \\
\text { Processos baseados em e controlados por web } \\
\text { intranet. Práticas operacionais orientadas por pré- } \\
\text { requisitos e especificaçōes CMM3. }\end{array}$ \\
\hline $\begin{array}{l}\text { Nivel } 5 \\
\text { Intermediário- } \\
\text { superior }\end{array}$ & \begin{tabular}{|l|} 
Equipes multidisciplinares, rotativas, de alta \\
especialização tecnológica. Soluçōes inovadoras \\
em engenharia de software e novas tecnologias a \\
partir de insights próprios. Desenvolvimento de \\
software em conjunto com centros globais.
\end{tabular} & $\begin{array}{l}\text { Formalização da gestão de risco. Avaliação de } \\
\text { performance em projetos por meio de métricas } \\
\text { quantitativas. }\end{array}$ & $\begin{array}{l}\text { Interação com o mercado global. Desenvolvimento de } \\
\text { produtos e soluçōes em tecnologias de última geração } \\
\text { (ex.: TV digital, PDAs, integraçãoo, telefonia celular - } \\
\text { CDMA, TDMA, GSM, iDEN). }\end{array}$ & $\begin{array}{l}\text { Transformação (reengenharia) dos processos } \\
\text { críticos do instituto. Ferramentas avançadas de } \\
\text { gestão de processos. Normas e padrōes de projetos } \\
\text { próprios (ex.: Prosces). Execução de projetos } \\
\text { envolvendo gestão de processos globais e } \\
\text { simultâneosis. Práticas operacionais orientadas por } \\
\text { pré-requisitos e especificaçōes CMM4. }\end{array}$ \\
\hline $\begin{array}{c}\text { Nivel } 6 \\
\text { Avançado }\end{array}$ & $\begin{array}{l}\text { Centro de P\&D de excelência mundial no } \\
\text { desenvolvimento de novas tecnologias (ex.: } \\
\text { games, grid computing, messaging, iDEN). }\end{array}$ & $\begin{array}{l}\text { Gestão de projetos de classe mundial. Gerência de } \\
\text { equipes fisicamente distantes. Capacidade pró- } \\
\text { ativa de reconhecer fraquezas. Prevenção da } \\
\text { ocorrência de falhas em processos e de defeitos } \\
\text { em produtos. }\end{array}$ & $\begin{array}{l}\text { Desenvolvimento de produtos e soluções de alta } \\
\text { complexidade, com grande capacidade de } \\
\text { personalização e adaptação para atender a } \\
\text { necessidades ainda não identificadas via P\&D (ex.: grid } \\
\text { computing, convergência). } \\
\text { Geração de spin-offs em decorrência da elevada } \\
\text { especializaçăoo tecnológica. }\end{array}$ & $\begin{array}{l}\text { Aprimoramento continuo dos processos e sistemas } \\
\text { operacionais, tanto a partir de avanços incrementais } \\
\text { nos processos existentes quanto a partir de novos } \\
\text { métodos e tecnologias. Práticas operacionais } \\
\text { orientadas por pré-requisitos e especificaçōes } \\
\text { CMM5. }\end{array}$ \\
\hline
\end{tabular}

Fonte: Figueiredo (2001).

Nota: Adaptado de e elaborado a partir de trabalho de campo que levou em consideração certas métricas específicas existentes: Capability Maturity Model - Software Engineering Institute (CMMSEI) e Project Management Body of Knowledge - Project Management Institute (PMBok - PMI).

iDEN: Integrated Digital Enhanced Network; PDAs: Personal Digital Assistants; CDMA: Code-Division Multiple Access; TDMA: Time Division Multiple Access; GSM: Global System for Mobile communication; Prosces: Processo Padrão de Desenvolvimento de Software do CESAR. 
cesso de deterioração das capacidades tecnológicas construídas até a década de 80 (CIMOLI; KATZ, 2003; KATZ, 2004). Segundo a perspectiva desses estudos, as atividades de P\&D estão cada vez mais concentradas em países industrializados. Nas economias latino-americanas, há certa tendência de especialização na produção de commodities e na atividade de produção industrial básica, sendo elas geralmente descritas como passivas em termos de aprendizagem e inovação. Outros estudos sugerem que a interação entre infra-estrutura tecnológica e empresas vem sendo seriamente deteriorada a partir da década de 90 , e que o processo de deterioração de capacidade tecnológica industrial caracteriza-se pela aprendizagem passiva do sistema nacional de inovação (CASSIOLATO; LASTRES, 2000; CASSIOLATO et al., 2001; VIOTTI, 1997, 2000).

Ocorre que tais argumentos e generalizações normalmente não são apoiados por evidências empíricas de primeira mão e suficientemente detalhadas em nível de organizações. Por isso, as conclusões que emergem de tais estudos não refletem a realidade de empresas e indústrias de países ou áreas em desenvolvimento. Especificamente, tais generalizações não se sustentam frente ao escrutínio empírico detalhado que a aplicação desta métrica permite.

\section{COMENTÁRIOS FINAIS E RECOMENDAÇÕES PARA ESTRATÉGIA INDUSTRIAL}

Este artigo buscou oferecer uma contribuição ao aprimoramento da gestão do processo de desenvolvimento tecnológico no contexto de economias em desenvolvimento, particularmente no Brasil. Para isso, procurou esclarecer o significado de certas terminologias relativas a aprendizagem tecnológica e inovação industrial e apresentou um modelo de mensuração que pode ser usado para examinar o processo de desenvolvimento industrial.

Tal iniciativa pode ser interpretada por alguns como "demasiadamente acadêmica". Contudo, convém reiterar que tem havido uso indiscriminado de certos termos relativos à inovação industrial sem a adequada fundamentação analítica e empírica. Essa prática pode deturpar e interferir negativamente no processo de desenho e na implementação de estratégias governamentais e empresariais de inovação. Por isso, foram apresentadas algumas definições e um modelo de mensuração alternativo para a acumulação de capacidade tecnológica. Isso é particularmente importante para o contexto da indústria no Brasil, pelos seguintes motivos:

- permite esclarecer as definições subjacentes ao desenho de estudos empíricos e de estratégias de inovação indus-

TABELA 1

Institutos da Amostra, por Tipo da Capacidade Tecnológica Acumulada, segundo Níveis de Competência

\begin{tabular}{|c|c|c|c|c|c|c|c|c|}
\hline \multirow{3}{*}{ Níveis de Competência } & \multicolumn{4}{|c|}{ Atividades de Engenharia e Gestão de Projetos } & \multirow{2}{*}{\multicolumn{2}{|c|}{ Produtos e Soluções }} & \multirow{2}{*}{\multicolumn{2}{|c|}{ Ferramentas e Processos }} \\
\hline & \multicolumn{2}{|c|}{ Engenharia de Software } & \multicolumn{2}{|c|}{ Gestão de Projetos } & & & & \\
\hline & №s Abs. & $\%$ & №s Abs. & $\%$ & №s Abs. & $\%$ & №s Abs. & $\%$ \\
\hline \multicolumn{9}{|l|}{ Capacidades Rotineiras } \\
\hline Nível 1 (Básico) & 18 & 100,0 & 18 & 100,0 & 18 & 100,0 & 18 & 100,0 \\
\hline Nível 2 (Extra básico) & 18 & 100,0 & 18 & 100,0 & 18 & 100,0 & 18 & 100,0 \\
\hline
\end{tabular}

\section{Capacidades Inovadoras}

\begin{tabular}{lcccccccc} 
Nível 3 (Inovação básica) & 18 & 100,0 & 18 & 100,0 & 18 & 100,0 & 18 & 100,0 \\
Nível 4 (Intermediário) & 18 & 100,0 & 14 & 77,7 & 17 & 94,4 & 8 & 44,4 \\
Nível 5 (Intermediário-superior) & 12 & 66,6 & 2 & 11,1 & 7 & 38,8 & 1 & 5,5 \\
Nível 6 (Avançado) & 1 & 5,5 & 0 & 0,0 & 1 & 5,5 & 0 & 0,0 \\
\hline
\end{tabular}

Fonte: Figueiredo e Marins (2005). 
trial. A partir de uma noção mais clara do real escopo do tema e das variáveis envolvidas, é possível calibrar, desenhar ou redesenhar estratégias com foco mais coerente com as necessidades do contexto industrial e tecnológico do Brasil e das suas diferentes regiões;

- auxilia a condução de novos estudos de inovação industrial fundamentados principalmente no trabalho de campo - e não apenas em análises de estatísticas oficiais - que possibilitam coletar evidências qualitativas e quantitativas de primeira mão e captar a realidade das atividades tecnológicas na indústria com adequado nível de detalhe e profundidade. Isso contribuiria para ampliar o debate para além das generalizações comuns - ou mesmo derrotistas - sobre o desenvolvimento tecnológico da indústria que, de tempos em tempos, emergem não apenas no Brasil, mas também na América Latina.

Mais especificamente, estudos baseados em amostra de dezenas de milhares de empresas, sem distinção intersetorial e à base de indicadores convencionais captados em um ponto no tempo podem gerar apenas uma mera "radiografia" de uma situação que nem sempre reflete a realidade industrial do país. Ou seja, estudos dessa natureza pouco contribuem para o entendimento da real dinâmica industrial - tão necessário para o desenho e redesenho de estratégias governamentais e empresariais.

A aplicação empírica do modelo de mensuração de capacidade tecnológica permite:

- avaliar, identificar e pontuar, de modo contínuo e à luz de taxonomias coerentes, o nível tecnológico dos setoreschave da indústria na economia brasileira;

- identificar a maneira e a velocidade com que certos setores têm acumulado suas capacidades tecnológicas ao longo do tempo. Ou seja, distinguir os setores mais dinâmicos dos mais lentos em termos de acumulação de capacidades tecnológicas pois, setores mais vagarosos em termos de acumulação tecnológica talvez necessitem de incentivos diferentes e de maior exposição às pressões competitivas internacionais;

- identificar os setores industriais que têm maior potencial e que devem receber maior atenção - em termos de recursos materiais, humanos, técnicos, organizacionais e financeiros - para aprofundar o desenvolvimento de capacidades tecnológicas;

- recomendar políticas específicas para disseminar atividades que conduzam ao desenvolvimento de capacidades tecnológicas nos setores mais relevantes para cada uma das regiões do Brasil.
De fato, atingir níveis de inovação próximos daqueles alcançados por empresas de países tecnologicamente avançados não é tarefa fácil. Porém, são duvidosas as perspectivas que advogam o avanço industrial de economias em desenvolvimento à base de proteção tarifária e subsídios, no intuito de resgatar a experiência histórica de certos países hoje tecnologicamente avançados (CHANG, 2002). Evidências e análises de estudos sobre inovação industrial realizados ao longo das últimas décadas - alguns citados aqui - sugerem que a gestão da acumulação tecnológica, no âmbito das empresas, associada a diferentes estratégias governamentais, que convergem para apoiar e estimular o desenvolvimento tecnológico na indústria, são fatores essenciais para que empresas, de economias emergentes sigam uma trajetória ascendente na intricada "escada" de capacidades tecnológicas.

Na verdade, a intensificação da globalização e da liberalização comercial não elimina a necessidade de intervenções governamentais à base de desenho e implementação de estratégias para suportar, direta e indiretamente, a acumulação de capacidade tecnológica industrial.

Assim, como sugere a perspectiva subjacente ao modelo apresentado no Gráfico 1, durante o processo de desenho de estratégias de inovação industrial é importante distinguir dois tipos de desenvolvimento de capacidade tecnológica: a rotineira (para usar) e a inovadora (para gerar e gerir mudança tecnológica). Enquanto os governos estiverem interessados em acelerar ambos os tipos de trajetória, serão necessários diferentes recursos e ações para cada caso. Por isso, as decisões relativas a essas duas trajetórias estão no coração das opções estratégicas de desenvolvimento industrial de um país.

Em termos de estratégia industrial, a questão-chave é não apenas calibrar o grau de incentivos a empresas - para a compra de máquinas e equipamentos ou para exportação, por exemplo (abordagem estática) - mas também estimular que um grande número de empresas se mova, com adequada velocidade, para a acumulação de níveis inovadores de capacidade tecnológica por meio de um contínuo processo de aprendizagem (abordagem dinâmica).

Por isso, no intuito de contribuir para facilitar a materialização de certos objetivos, tanto governamentais como empresariais - por exemplo, o alcance de alto nível de desempenho inovador e exportador, com base em uma perspectiva de 2020, para certos segmentos da indústria no Brasil -, sugere-se a criação de metas de desenvolvimento de capacidade tecnológica. Isso significa criar prazos para 
o alcance de diferentes tipos e níveis de capacidades tecnológicas para os vários setores industriais no longo prazo, com avaliação a cada dois anos. Essa medida possibilitaria que ajustes periódicos, em termos, por exemplo, de fortalecimento e/ou reorganização da infra-estrutura tecnológica e de processos de aprendizagem, pudessem ser implementados, a fim de contribuir para a materialização dos níveis tecnológicos desejados. O processo de elaboração e implementação das metas de desenvolvimento de capacidade tecnológica poderia envolver lideranças empresariais, governamentais, acadêmicas e de outras organizações da sociedade comprometidas com o desenvolvimento industrial e tecnológico nacional.

\section{NOTAS}

Este artigo foi gerado no âmbito do Programa de Pesquisa em Gestão da Aprendizagem Tecnológica e Inovação Industrial no Brasil, da Escola Brasileira de Administração Pública e de Empresas (Ebape), Fundação Getúlio Vargas (FGV).

1. Para uma breve revisão de alguns desses estudos, ver Figueiredo (2004).

2. Ver Penrose (1959); Hollander (1965), dentre outros.

3. Ver Freeman (1974; 1982); Rosenberg (1976); Rothwell (1977); Nelson e Winter (1982); Dosi (1988a; 1988b); Dietrickx e Cool (1989); Teece et al. (1990); Pavitt (1984; 1991); Pavitt e Wald (1971) e muitos outros.

4. Ver Katz (1976); Maxwell (1981); Dahlman e Fonseca (1978) e vários outros sumariados em Katz (1987).

5. Para uma extensiva revisão desses estudos, ver Figueiredo (2001).

6. Ver, por exemplo, Hobday (1995); Kim (1997; 1998); Dutrénit (2000); Figueiredo (2001).

7. Há uma ampla literatura na qual se busca distinguir entre os termos capacidades e capacidades tecnológicas. Mais precisamente, na língua inglesa, os diferentes termos usados são, por exemplo, capabilities, competence e competencies. Porém, não é o objetivo deste artigo discutir as diferentes perspectivas, mas apresentar a definição mais ampliada do termo capacidade tecnológica no contexto de economias em desenvolvimento. Por isso, daqui em diante, será usado apenas o termo capacidade tecnológica. Não obstante, é importante lembrar que o termo capacitação tecnológica refere-se ao processo de acumulação de capacidades tecnológicas por meio dos vários processos subjacentes de aprendizagem.

8. Ver Katz (1976); Lall (1982; 1987); Dahlman e Westphal (1982); Bell (1982); Westphal et al. (1984); Scott-Kemmis (1988).

9. Essa perspectiva ampla para capacidade tecnológica também é encontrada na literatura sobre gestão da inovação no contexto de empresas inovadoras de economias industrializadas (LEONARDBARTON, 1995).

10. Para mais detalhes sobre essa perspectiva, ver Bell e Pavitt (1993; 1995) e Bell (1996).
11. Há uma literatura clássica sobre a relação simbiótica entre tecnologia e organização. Ver Rosenberg (1976; 1982), Salomon (1984), Pavitt (1985)

12. Ver exemplos em Bell et al. (1982), Leonard-Barton (1995), Dutrénit (2000) e Figueiredo (2001).

13. Discussões detalhadas sobre a limitação desses indicadores para o contexto de empresas em economias em desenvolvimento são desenvolvidas em Bell e Pavitt (1993, 1995); Ariffin e Bell (1999); Ariffin (2000) e Figueiredo (2001; 2003a; 2003b).

14. É o caso, por exemplo, do desenho da Pintec (IBGE) e de seu desdobramento refletido no estudo 'Inovação, padrões tecnológicos e desempenho de firmas industriais brasileiras', realizado pelo Instituto de Pesquisa Econômica Aplicada - Ipea. Não obstante, um dos méritos do estudo do Ipea é chamar a atenção para as implicações positivas dos esforços das empresas em 'inovação tecnológica' para a sua performance econômica.

15. Outros modelos descrevem as trajetórias de acumulação de capacidade tecnológica adotando perspectivas diversas. O 'ciclo reverso de produto' de Hobday (1995) está mais ligado à acumulação de capacidades para os mercados exportadores, ao passo que o modelo 'aquisição-assimilação-aprimoramento' de Kim (1997) tem mais a ver com a acumulação de capacidade para produtos do que para outros tipos de funções tecnológicas (por exemplo, equipamento, gestão de projetos, processos e organização da produção).

16. O processo de adaptação e validação desse modelo para sua aplicação empírica em um estudo centrado na indústria de aço levou aproximadamente um ano. As principais atividades desse processo envolveram a seleção das funções tecnológicas relevantes, a coleta e a classificação das atividades específicas para expressar os diversos níveis de capacidade tecnológica e uma contínua validação com diferentes profissionais de empresas de aço e especialistas da indústria.

17. Ver, por exemplo, Ariffin (2000) e Ariffin e Figueiredo (2003) para a indústria eletrônica; Tacla e Figueiredo (2003) para indústria de bens de capital fornecedora de sistemas de produção para a indústria de celulose e papel. Uma adaptação para a indústria de motocicletas e bicicletas foi realizada em Figueiredo (2005). No âmbito do Programa de Pesquisa em Gestão da Aprendizagem Tecnológica e Inovação Industrial no Brasil, da Ebape/FGV, adaptações têm sido feitas em estudos empíricos de desenvolvimento tecnológico em empresas de diferentes setores industriais no Brasil: metal-mecânico, linha branca (geladeiras, máquinas de lavar, ar condicionado e fornos microondas), componentes eletrônicos, telefonia celular e fixa.

18. O estudo também examinou duas fontes utilizadas pelos institutos pesquisados para construir suas capacidades tecnológicas: processos de aprendizagem intra-organizacionais e ligações com empresas e componentes da infra-estrutura tecnológica (universidades, institutos de pesquisa, centros de formação e treinamento e laboratórios), ver Figueiredo e Marins (2005).

\section{REFERÊNCIAS BIBLIOGRÁFICAS}

ANDREASSI, T.; SBRAGIA, R. Fatores determinantes do grau de novatividade das empresas: um estudo utilizando a técnica de análise discriminante. Série de working papers. São Paulo, FEAUSP, n. 01/004, 2002. Disponível em:

<http://www.ead.fea.usp.br/wpapers>.

ARIFFIN, N. The internationalization of innovative capabilities: the Malaysian electronics industry. 2000. Thesis (D. Phil.) SPRU, University of Sussex, Brighton, 2000. 
ARIFFIN, N.; BELL, M. Firms, politics and political economy: patterns of subsidiary-parent linkages and technological capability-building in electronics TNC subsidiaries in Malaysia. In: JOMO, K. S.; RASIAH, R.; FELKER, G. (Ed.). Industrial technology development in Malaysia. London: Routledge, 1999.

ARIFFIN, N.; FIGUEIREDO, P.N. Internacionalização de capacidades tecnológicas: implicações para estratégias governamentais e empresariais de inovação e competitividade da indústria eletrônica no Brasil. Rio de Janeiro: FGV, 2003.

BELL, M. Overheads and notes on lectures and seminars. SPRU, University of Sussex, 1997. (Technology and Development Course, MSc in Technology and Innovation Management Course)

Technology transfer to transition countries: are there lessons from the experience of the post-war industrializing countries? In: DYKER, D. (Ed.). The Technology of Transition: Science and technology policies for transition countries. Central European: University Press, 1996. p. 63-94.

Technical change in infant industries: a review of the empirical evidence. Brighton: SPRU, University of Sussex, 1982

BELL, M.; SCOTT-KEMMIS, D.; SATYARAKWIT, W. Limited learning in infant industry: a case study. In: STEWART, F.; JAMES, J. (Ed). The Economics of New Technology in Developing Countries. London: Frances Pinter, 1982

BELL, M.; PAVITT, K. The development of technological capabilities. In: UL HAQUE, I.; BELL, M.; DAHLMAN, C; LALL, S.; PAVITT, K. Trade, technology and international competitiveness. Washington, DC: The World Bank, 1995. p. 69-101.

Technological accumulation and industrial growth: contrast between developed and developing countries. Industrial and Corporate Change, v. 2, n. 2, p. 157-210, 1993.

CASSIOLATO, J.E.; LASTRES, H.M.M. Local Systems of Innovation in Mercosur Countries. Industry and Innovation, v. 7 , n. 1, p. $33-54,2000$.

CASSIOLATO, J.E; SZAFIRO, M.; LASTRES, H.M.M.; VARGAS, M. Local systems of innovation in Brazil, development and transnational corporations: a preliminary assessment based on empirical results of a research project. In: DRUID's NELSON-WINTER CONFERENCE, Conference Paper... Copenhagen, Denmark, June 2001.

CHANG, H-J. Kicking away the ladder - development strategy in historical perspective. London: Anthem Press, 2002.

CIMOLE, M.; KATZ, J. Structural reforms, technological gaps and economic development: a Latin American perspective. Industrial and Corporate Change, v. 12, n. 2, p. 387, 2003.

COHEN, W.M.; LEVIN, R.C. Empirical studies innovative activity and market structure. In: SCHMALENSEE, R.; WILLIG, R. (Org.). Handbook of Industrial Organization. Amsterdan: North Holland, 1989.

COHEN, W.M.; LEVINTHAL, D.A. Absorptive capacity: a new perspective on learning and innovation. Administrative Science Quartely, v. 35, n. 1, p. 128-52, 1990.

DAHLMAN, C.; ROSS-LARSON, B.; WESTPHAL, L.E. Managing technological development: lessons from the newly industrializing countries. World Development, v. 15, n. 6 , p. $759-75,1987$.
DAHLMAN, C.; FONSECA, F. From technological dependence to technological development: the case of the USIMINAS steel plant in Brazil. Working Paper 21, IBD/ECLA Research Programme, 1978.

DAHLMAN, C.; WESTPHAL, L. Technological effort in industrial development: an interpretative survey of recent research. In: STEWART, F.; JAMES, J. (Ed.). The economics of new technology in developing countries. London: Frances Pinter, 1982. p. 105-137.

DANIELS, P.L. National technology gaps and trade - an empirical study of the influence of globalisation. Research Policy, n. 25, p. 1189-1207, 1997.

DIETRICKX, I.; COOL, K. Asset stock accumulation and sustainability of competitive advantage. Management Science, v. 35 , p. $1504-1511,1989$.

DOSI, G. Sources, procedures, and microeconomic effects of innovation. Journal of economic Literature, v. 26, p. 1.120$1.171,1988 \mathrm{a}$

The nature of the innovative process. In: DOSI, G.; FREEMAN, C.; NELSON, R.; SILVERBERG, G.; SOETE, L. (Ed.). Technical change and economic theory. London: Pinter Publishers, 1988b.

DUTRÉNIT, G., Learning and knowledge management in the firm: from knowledge accumulation to strategic capabilities. Cheltenham, UK; Northampton, MA, USA: Edward Elgar Publishing, 2000.

FIGUEIREDO, P.N. Plugging into globalisation to stay alive and move ahead or standing still to fall behind? Evidence of technological capability building from three sets of manufacturing firms in Northern Brazil. In: DRUID SUMMER CONFERENCE, 27-29 June 2005, Copenhagen. Paper... Copenhagen, Denmark, 2005. Disponível em:

$<$ http://www.druid.dk/conferences/summer2005/papers/ds2005502.pdf $>$.

Aprendizagem tecnológica e inovação industrial em economias emergentes: uma breve contribuição para o desenho e implementação de estudos empíricos e estratégias no Brasil. Revista Brasileira de Inovação, v. 3, n. 2, p. 323-362, jul./dez. 2004.

Aprendizagem tecnológica e performance competitiva. Rio de Janeiro: FGV, 2003a.

Learning, capability accumulation and firms differences: evidence from latecomer steel. Industrial and Corporate Change, v. 12 , n. 3, p. 607-643, 2003b.

Does technological learning pay off? Implications for inter-firm differences in operational performance improvement. Research Policy, v. 31, n. 1, p. 73-94, 2002.

Technological learning and competitive performance. Cheltenham, UK; Northampton, MA, USA: Edward Elgar Publishing, 2001.

FIGUEIREDO, P.N.; MARINS, L. Desenvolvimento de competências tecnológicas inovadoras em Tecnologia de Informação e Comunicação (TIC) no Brasil: evidências de uma amostra de organizações relacionadas à pesquisa e desenvolvimento $(\mathrm{P} \& \mathrm{D})$ - um exame preliminar. Rio de Janeiro, Fundação Getúlio Vargas, Ebape, 2005. (Relatório Final).

FREEMAN, C. The Economics of Industrial Innovation. London: Frances Pinter, 1982. 
The Economics of Industrial Innovation.

Harmondsworth, England: Penguin, 1974.

GERSCHENKRON, A. Economic backwardness in historical perspective. Cambridge, MA: Harvard University Press, 1962.

HOBDAY, M. Innovation in East Asia: the challenge to Japan. Aldershot: Edward Elgar, 1995.

HOLLANDER, S. Gargalos da indústria. São Paulo: Iedi, 2003.

The sources of increased efficiency: a study of Du Pont rayon plants. Cambridge, MA: MIT Press, 1965.

JACOBSSON, S.; OSKARSSON C. Educational statistics as an indicator of technological activity. Research Policy, v. 24, p. 127-36, 1995.

KANNEBLEY, S. Jr. Características das firmas inovadoras no Estado de São Paulo: uma análise empírica a partir da Paep. Série Economia, FEA-RP/USP, 2003. (Texto para discussão, n. 40).

KATZ, J. The limits of the prevailing orthodoxy: Technology and education as restrictions to productivity growth and international competitiveness in Latin America. In: DRUID SUMMER CONFERENCE, 14-16 June 2004. Paper... Elsinore, Denmark, 2004.

Domestic technology generation in LDCs: a review of research findings. In: (Ed.). Technology generation in Latin American manufacturing industries. New York: St Martin's Press, 1987.

Importación de tecnología, aprendizaje y industrialización dependiente. México: Fondo de Cultura Económica, 1976.

KIM, L. Crisis construction and organisational learning: capability building in catching-up at Hyundai Motor. Organization Science, v. 9, p. 506-521, 1998.

Imitation to Innovation: The Dynamics of Korea's Technological Learning. Boston, MA: Harvard Business School Press, 1997.

KUMAR, N.; SIDDHARTHAN, N.S. Technology, Market Structure and Internationalization: Issues and Policies for Developing Countires. London \& New York: Routledge and UNU Press, 1997.

LALL, S. Technological capabilities. In: SALOMON, J. J. et al. (Ed.). The uncertain quest: science technology and development. Tokyo: UN University Press, 1994.

Technological capabilities and industrialisation. World Development, v. 20, n. 2, p. 165-186, 1992.

Learning to industrialise: the acquisition of technological capability by India. London: Macmillan, 1987.

Technological learning in the Third World: some implications of technology exports. In: STEWART, F.; JAMES, J. (Ed.). The economics of new technology in developing countries. London: Frances Pinter, 1982.

LEORNARD-BARTON, D. Wellsprings of knowledge: building and sustaining the sources of innovation. Boston, MA: Harvard Business School Press, 1995.

MACEDO, P.B.R.; ALBUQUERQUE, E.M. P\&D e tamanho da empresa: evidência empírica sobre a indústria brasileira. Revista Estudos Econômicos, v. 29, n. 3, p.343-365, 1999.
MANSFIELD, E.; TEECE, D; ROMEO, A. Overseas research and development by US-based firms. Economica, v. 46, p. 187 196, May 1979.

MAXWELL, P. Technological Policy and Firm Learning Efforts in Less Developed Countries: a Case Study of the Experience of the Argentina Steel Firm Acindar SA. Thesis (D.Phil) - SPRU, University of Sussex, 1981.

MLAWA, H. The Acquisition of Technology, Technological Capability and Technical Change: a Study of the Textile Industry in Tanzania. Thesis (D.Phil) - Science Policy Research Unit - Institute of Development Studies, University of Sussex, Sussex, UK, 1983.

NELSON, R.; WINTER, S. An Evolutionary Theory of Economic Change. Cambridge, MA: Harvard University Press: 1982.

OECD. OSLO manual: proposed guidelines for collecting and interpreting innovation data. Paris: OECD: Statistical Office of the European Communities, 1997.

PACK, H. Productivity, technology and industrial development: a case study in textiles. New York: Oxford University Press, 1987.

PATEL, P. Localised production of technology for global markets. Cambridge Journal of Economics, v. 19, p. 141-153, 1995.

PATEL, P.; PAVITT, K. The technological competencies of the world's largest firms: complex and path-dependent, but not much variety. Research Policy, v. 26, p. 141-156, 1997.

PAVITT, K. Key characteristics of the large innovating firm. British Journal of Management, v. 2, p. 41-50, 1991.

Technology transfer among the industrially advanced countries: an overview. In: ROSENBERG, N.; FRISCHTAK, C. (Ed.). International technology transfer: Concepts, measures, and comparisons. New York: Praeger Publishers, 1985

Sectorial Patterns of Technical Change: Towards a Taxonomy and a Theory. Research Policy, v. 13, p. 343-373, 1984

PAVITT, K.; WALD, S. The Conditions for Success in Technological Innovation. Paris: OECD, 1971.

PENROSE, E. T. The theory of the growth of the firm. Oxford: Basil Blackwell, 1959.

QUADROS, R.; FURTADO, A.; BERNARDES, R.; FRANCO, E. Technological innovation in Brazilian industry: an assessment based on the São Paulo innovation survey. Technological Forecasting and Social Change, v. 67, n. 2-3, p. 203-219, June 2001 .

ROSENBERG, N. Política de ciência e tecnologia no II PBDCT (1976). Revista Brasileira de Inovação, v. 2, n. 1, p. 179-211, 2003.

Inside the Black Box: Technology and Economics. Cambridge: Cambridge University Press, 1982.

Perspectives on Technology. Cambridge: Cambridge University Press, 1976

ROTHWELL, R. The characteristics of successful innovators and technically progressive firms. $R \& D$ Management, v. 7, p. 191-206, 1977.

SALOMON, J.J. What is technology? The issue of its origins and definitions. History and Technology. London: Harwood Academic Publishers GmbH, 1984. p. 113-156. v. 1. 
SCOTT-KEMMIS, D. Learning and the accumulation of technological capacity in Brazilian pulp and paper firms. World Employment Programme Research, 1988. (Working Paper, 187, p. 2-22).

STEWART, F.; JAMES, J. Introduction. In: (Ed.).

The Economics of New Technology in Developing Countries. London: Frances Pinter, 1982.

TACLA, C.L.; FIGUEIREDO, P.N. Processos de aprendizagem e acumulação de capacidades tecnológicas: evidências de uma empresa de bens de capital no Brasil. Revista de Administração Contemporânea, v. 7, n. 3, p. 101-126, 2003.

TEECE, D.; PISANO, G.; SHUEN, A. Firm capabilities, resources, and the concept of strategy: four paradigms of strategic management. CCC Working Paper, n. 90-8, Berkeley, University of California, 1990.

VERA-CRUZ, A. How Firms's Culture Shapes Technological Behaviour: the Case of Two Mexican Breweries. Special Issue, 2002.

VIOTTI, E.B. Passive and active national learning systems. A framework to understand technical change in late industrializing economies and some evidences from a comparative study of Brazil and South Korea. In: INTERNATIONAL CONFERENCE ON TECHNOLOGY POLICY AND INNOVATION, 4., 28-31 August 2000, Curitiba. Papers... Curitiba, Brazil, 2000.

Passive and active national learning systems. A framework to understand technical change in late industrializing economies and some evidence from a comparative study of Brazil and South Korea. Thesis (D.Ph) - The New School University, 1997. Unpublished.

WESTPHAL, L.E.; KIM, L.; DAHLMAN, C.J. Reflections of Korea's acquisition of technological capability. Washington, DC: World Bank Research Department, Economics and Research Staff, 1984. (Report DRD77).

WORTMAN, M. Multinationals and the internationalisation of R\&D: new developments in German companies. Research Policy, v. 19, p. 175-183, 1990.

Paulo N. Figueiredo: Ph.D. em gestão da tecnologia e inovação pela University of Sussex, Reino Unido. Professor da Escola Brasileira de Administração Pública e de Empresas da Fundação Getúlio Vargas. Coordena o Programa de Pesquisa em Gestão da Aprendizagem Tecnológica e Inovação Industrial no Brasil (Ebape/FGV). É autor do livro Technological Learning and Competitive Performance (pnf@fgv.br).

Artigo recebido em 18 de março de 2005.

Aprovado em 7 de abril de 2005. 